\title{
The impact of Internet-based Financing on China's Commercial Banks and Countermeasures
}

\author{
Min Yu \\ Guizhou University of Finance and Economics
}

\begin{abstract}
It has had a great impact on China's financial industry since the birth of internet-based financing. Information system, such as social networking, mobile payments, big data and cloud computing has developed a lot, which provides technical support for the development of internet-based financing, and also has great impact on commercial banks today. The commercial banks must adapt to the information society brought by the internet-based financing competition and take effective countermeasures to it. The arrival of internet-based financing is both an opportunity and a challenge to commercial banks. Based on the analysis of the internet-based financing's impact on commercial banks, the advantages in economic function of the internet-based financing and commercial banks, the article gives commercial banks the countermeasure to internet-based financing.
\end{abstract}

\section{Keywords}

Internet-based financing; commercial bank; economic function; influence; countermeasure

\section{互联网金融对我国商业银行的影响及对 策分析}

\author{
余敏 \\ 贵州财经大学, 贵阳, 550025, 中国
}

\begin{abstract}
摘要: 互联网金融诞生之后，对我国金融业产生很大影响。社交网络、移动支付、大数据和 云计算等计算信息系统的发展，为互联网金融发展提供了技术支持，至今其对商业银行的影 响是全方位的。银行必须适应信息社会带来的互联网金融竞争，采取有效应对措施。互联网 金融的到来既是机遇也是挑战，本文在分析了互联网金融对银行的冲击后，对互联网金融与 银行的经济功能优势分别作了比较分析，在此基础上提出了商业银行应对互联网金融的应对 策略。
\end{abstract}

关键词：互联网金融；商业银行；经济功能；影响；对策 


\section{1.互联网金融的内涵}

最早给出互联网金融定义的是谢 平和周传伟, 认为互联网金融是既不 同于商业银行间接融资也不同于资本 市场直接融资的第三种金融融资模 式, 并且认为互联网金融已经并且将 对金融模式造成颠覆性的影响。从市 场上的参与主体来看, 互联网企业将 其客户转换为可以实现从金融业务上 获取收入的手段可以称为互联网金 融; 从金融本质以上看，互联网金融 是资金供给和需求双方抛弃实体中介 机构, 利用互联网技术实现供需双方 的直接交易, 提升了资本流动效率, 实现资产的高效配置。《中国金融稳 定报告》（2014），互联网金融十互 联网和金融的融合, 是借助于互联网 和移动通信技术实现资金的融通、支 付和信息中介的新型金融模式。广义 包括作为非金融机构的互联网企业提 供的金融服务也包括金融企业通过互 联网开展的业务, 狭义指互联网企业 开展的基于互联网技术的金融服务即 “外行领导下的金融服务”。

\section{2.互联网金融兴起原因}

在金融市场上，一方是资金供给 方对财富保值增值的需求, 另一方是 资金需求方特别是通过正常的融资途 径难以融入资金的需求方对融资的需 求，双方由于信息的不对称造成交易 难以达成。另一方面, 商业银行长期 以来一直保持着其固有的经营模式, 难以满足众多资金供需双方的需求, 这给互联网金融的发展提供了巨大的 市场机会。而众多的熟悉互联网金融 的青年一代逐渐成为社会上的主流, 他们成为了巨大的网络用户群体。从 数据上看，2016 年我国网民达到 7.31 亿, 网上银行、网上支付用户达
到 4.75 亿，电子商务交易金额达到 26.1 万亿元。互联网金融很好地满足 了互联网时代客户群体消费和融资需 求的改变，促进了民间金融的信息对 称，并且互联网金融具备 “信息收集 成本低, 交易便捷” 的特点, 促使了 其迅速发展。

\section{3.互联网金融业务主要模式}

\section{1.金融信息化即传统金融机构的电子 商务化}

传统金融机构为适应客户的需 求，在继续提供传统业务服务的同 时, 积极利用互联网作为新的服务手 段, 建立金融网站, 提供网络金融服 务。它是原有的金融机构与网络信息 技术相结合的结果。这种模式的主要 特点在于同时以传统分支机构和金融 网络向客户提供服务, 客户可以自己 选择需要的服务模式, 即实现了在线 业务与离线业务的结合。如在我国由 传统金融机构所开设的网上银行、网 上证券和网上保险就属于这种模式。

\section{2.第三方支付模式}

第三方支付是通过非银行的第三 方机构所经营的网上支付平台，通过 商家、消费者和银行直接的关系，向 其提供货币支付和资金结算服务交易 的一种资金代管新型担保支付模式。 它实际上电子货币的流转方式。第三 方支付起源于 20 世纪 80 年代美国 ISO 制度, 即独立销售组织。我国第三方 支付发展历史并不长, 1998 年成立的 首信易支付具有第三方支付平台的雉 形, 2003 年中国银联逐步实现了各银 行间的交易清算, 具有了第三方支付 的色彩, 目前我国第三方支付市场已 经基本成熟，2005 年互联网进入中国 金融市场, 网银支付业态成熟, 支付 
宝、财付通、首信易支付等逐步成为 主要的第三方支付平台，促进了第三 方支付的发展和成熟。目前我国已经 有 300 多家企业获得了第三方支付牌 照。

\section{3.网络借贷模式}

网络借贷是个人与个人之间不通 过金融中介，直接通过网络平台实现 信息交互, 实现自助的借贷行为。在 网络平台上，借贷双方可以实现借贷 信息发布、投资咨询、资金流通、合 同签署以及其他增值服务。2006 年, 中国第一个从事小额信贷的 P2P 平台 宜信在北京成立, 此后, P2P 行业在我 国发展迅速。传统模式即为标准的 $\mathrm{P} 2 \mathrm{P}$, 即点对点的金融信息服务平台, 平台以服务费、管理费用或者行业早 期较为普遍的以赚取交易双方的利差 等方式作为盈利手段。在此基础上发 展出了以拍拍贷为代表的纯正欧美血 统的无抵押无担保模式、以人人贷为 代表的中国式房产抵押和第三方贸底 模式、以宜信为代表的伪 P2P 风险备 用金模式、以有利网为代表的担保公 司、小贷公司担保模式、以陆金所为 代表的金融机构信用和担保公司担保 模式。发展至今, 我国网贷总体呈现 以下趋势：平台增速减缓，问题平台 增多、网贷产品期限增长, 收益率下 降、网贷平台地区集中度较高, 地区 下沉趋势初现、网贷人气还将扩大 等。

\section{4. 网络众筹}

是利用互联网平台，共同筹集一 部分资金以支持其他个人或组织的发 展或各种项目的运作。众筹实际上是 项目发起人通过网络众筹平台向出资 人介绍项目情况，并募集小额资金支 持的一种融资方式, 这是一种打破传 统的融资模式, 利用互联网平台, 使
广大草根可以获得从事某个项目的资 金，资金来源也更加广泛，既有利于 发起人解决资金短缺问题, 又为普通 投资者增加了新的投资渠道。

\section{5. 大数据金融}

指利用大数据开展的金融服务, 即针对海量数据, 经过互联网、云计 算等信息化处理方式, 对客户消费数 据实行实时分析，可以为金融企业提 供客户全方位的信息，通过分析和挖 掘客户的交易和消费信息掌握客户的 消费习惯，并准确预测客户行为，提 高金融服务平台效率和降低信贷风 险。主要有以阿里小贷为代表的平台 模式和以京东、苏宁金融为代表的供 应链模式。平台模式是企业基于互联 网电子商务平台基础提供的资金融通 的金融服务，或企业通过在平台上凝 聚的资金流、物流、信息流，组成以 大数据为基础的平台来整合金融服 务。供应链模式是供应链中的核心企 业利用所处产业链上下游，充分整合 供应链资源和客户资源而为其它参与 方提供融资渠道的金融模式。

\section{4.互联网金融的发展对商业银行的冲击}

\section{1.互联网金融的发展侵占了部分商业 银行业务}

支付结算业务属于商业银行三大 传统业务之一，对商业银行来说是一 项基础业务, 但随着互联网金融支付 的发展, 直接威胁到商业银行在支付 领域的重要性, 商业银行面临着被边 缘化的困境，表现在互联网金融脱离 传统金融机构中介，交易双方利用第 三方支付直接进行资金交付，资金在 传统银行体系之外循环。随着互联网 支付系统的技术发展, 支付宝和财付 通两大行业龙头在 PC 端共占据 $67.5 \%$ 
的市场份额, 移动端占比更高, 占据 近 90\%的市场 份额，对于商业银行的 支付业务冲击明显加剧。

\section{2.商业银行的收入受到影响}

商业银行的传统收入主要集中在 其资产负债核心业务，收入来源有利 差决定，主要依靠的是大企业、高端 客户的存贷业务获取利息收入，以及 依靠传统的中间业务获取非利息收 入。其经营模式陈旧，如果不做突破 及改进很难适应社会发展的需求。在 互联网金融模式下，大数据分析技术 可以根据客户的消费模式以及消费习 惯对客户进行甄选，能够快捷、高 效、低成本的实现交易达成, 提高了 金融需求和服务渠道的相互融合，一 定程度上改变了过去依靠商业银行的 物理网点服务以及盈利模式。

\section{3. 客户对银行的粘性下降, 加重了银 行的金融脱媒现象}

互联网金融企业能为客户提供多 元化的金融服务, 让客户的日常金融 交易都通过平台完成。如 “支付宝” 和 “微信支付” 两款产品, 都可以让 客户实现购物、转账汇款、信用卡还 款、缴纳生活费、购买机票车票、购 买电影票、商场购物、支付学费甚至 打车都可以通过其进行, 减少了客户 与银行的业务量, 导致客户粘性下 降, 加重了银行的金融脱媒现象。

\section{5.互联网金融与商业银行的经济功能优 势比较分析}

\section{1. 商业银行在经济中所起的功能分析}

\subsection{1 商业银行具备经济调节功能}

第一、商业银行是货币政策传递的主 要渠道

我国中央银行通过调整法定存款 准备金率、再贴现率、优惠利率、特 殊的信贷政策、公开市场操作等途径 来对经济进行调节, 而这些过程中, 商业银行都是重要的参与者。只要中 央银行发行货币、控制通货膨胀率等 经济调控的职能继续存在, 商业银行 作为货币政策传递的主要渠道功能就 不会改变。而互联网金融并不具备这 样的功能。

第二、商业银行具备货币创造职能

由于商业银行是法定允许吸收存 款的金融机构，其通过吸收存款发放 贷款的运行机制可以创造出数倍于原 始存款的派生存款, 具备货币创造功 能。这一点是受到现行法律制度的认 可和监管的。

\subsection{2 商业银行在复杂金融交易、风险 管理及防控上的优势明显}

相较于互联网金融来说, 商业银 行能够提供大额的、复杂的金融交 易, 能够提供多种金融衍生工具及其 组合的交易来满足客户需求, 商业银 行凭借多年来累积的经验, 拥有专业 的团队对不同金融工具的组合设计, 为企业量身定制风险防范的不同手 段, 降低企业的风险及融资成本。目 前来看, 互联网金融很难具备这样的 功能。

\subsection{3 商业银行的资金实力雄厚、公信 力高、行业准入门槛高}

截至 2016 年末, 全国性商业银行 资产总额 130.07 万亿元，其资金实力 雄厚是互联网金融企业望其项背的, 同时, 商业银行自成立以来的稳健经 营在人民群众心中树立了很好的形 象, 人们对其信任度极高。由于对金 
融监管的需要, 监管当局对开设新银 行的门槛高可以理解的。

\section{2.互联网金融区别于银行的优势分析}

\subsection{1 互联网金融网络用户群增长迅 速, 其增长率及成长性高于商业银 行的传统客户}

互联网技术的发展为互联网金融 的发展奠定了数量庞大、分布广泛、 后续增长强劲的的客户基础, 互联网 金融对网民的生活形态产生了越来越 重要的影响。而商业银行为了确保客 户的信息和资金安全，对客户的信息 是相对封闭的, 也体现了银行之间为 了留住客户的传统防卫型竞争模式。 这种信息不共享的经营方式造成了各 家商业银行只能依靠自我累积来慢慢 吸引和维护客户，而互联网金融拥有 增长强劲的客户基础将对商业银行形 成明显的挑战。

\subsection{2 互联网金融的理财产品销售门槛 低, 理财产品销售增长迅速}

随着第三方支付的广泛流行，理 财产品的销售也随之快速增长, 典型 案例就是 2013 年 5 月 29 日成立的余 额宝, 成立五个月后就成为我国资产 规模最大的货币基金，余额宝之所以 增长如此迅速, 是因为其拥有一个客 户基础广大的互联网销售平台即支付 宝。相比银行理财产品最低五万元的 投资门槛相比，余额宝 1 元的起步投 资, 让每一个支付宝客户都可以将自 己闲散的小额资金进行理财，这极大 地增加了互联网金融理财产品的销 售, 同时也造成了银行的部分存款流 失。

\subsection{3 互联网金融的信贷信息收集较商 业银行更为便捷和广泛}

中小企业由于资信实力不足，抗 风险能力相对较差, 对资金需求 “急、频、短” 的特点难以在商业银 行获得足够的融资需求。而互联网电 子商务平台和第三方支付机构在运营 中积累了大量的客户，这些客户的交 易记录、买卖双方评价等信息构成了 重要的信用记录, 这有利于互联网金 融机构通过累积这些信息建立起自己 的信用评价体系和信用数据库, 通过 对这些信息的分析，达到消除信息不 对称, 实现对企业进行有效甄选发放 贷款。

\section{6. 商业银行应对互联网金融发展的应对 措施}

\section{1 银行要充分挖掘自身优势, 转变传 统的经营观念}

银行要充分利用自身资产实力雄 厚、社会信誉度高、机构网点众多等 自身优势, 转变经营观念, 改变过去 认为一家独大的思想观念, 充分认识 到互联网金融利用数据和电子商务方 面的优势, 在金融市场上产生了新的 经营模式, 而这些新的经营模式相较 于传统的经营模式来说更加方便快 捷, 更好的满足了客户的需要, 商业 银行需要充分认识到这一点, 重新审 视自己的业务, 并做出相应的改进甚 至改革, 才能在未来的金融市场上夺 得先机。

\section{2 加强提升科技研发与应用水平}

商业银行要利用网络信息技术的 发展, 在软硬件方面力求与当代科技 发展实现融合。商业银行在互联网金 融信息系统的改造应该包括电子商务 
平台、数据库系统支付结算系统和征 信查询系统等, 银行可以考虑与互联 网金融企业的进一步深入合作，以免 重头构建或发展相关系统耗时费力, 错过市场机会。

\section{3 加强同互联网金融企业的合作, 合 作中寻求共赢}

从现在的发展状况来看, 互联网 金融企业与商业银行既是竞争对手, 也是合作伙伴。互联网金融的发展态 势强劲, 商业银行不能选择逃避其存 在, 也不能运用恶意竞争的手段对其 进行排斥, 而是应该更加开放的与其 建立合作共赢的关系, 充分发挥各自 的优势, 共同开发更加能够满足人们 需求的金融产品和支付工具, 实现互 利互惠的合作方式。商业银行应该积 极探索与互联网金融企业共享商户资 源和客户信息, 借助互联网金融累积 的海量信息交易数据库, 发挥银行自 身的风险管理优势，联合打造信贷新 产品, 开发新的客户群体, 提高对中 小企业的融资服务, 从而增加银行营 业收入。

\section{4 重视客户体验}

互联网金融企业个性化的金融产 品、低进入门槛以及其方便快捷的操 作流程吸引了越来越多的客户, 这也 造成了商业银行的部分客户资源流 失。商业银行要想在互联网金融领域 中占据重要地位, 必须站在客户的角 度, 运用数据分析客户的消费习惯和 投资偏好，根据客户不同需要量身设 计不同的金融产品，简化服务流程， 减少贷款审批环节, 为客户提供更为 快捷便利的服务。

\section{5 吸引和培养复合型人才}

从某种某种程度上来说, 银行在 互联网金融领域的竞争主要表现为人 才竞争, 因此对人才的培养和吸引就 显得尤为重要。由于互联网金融的复 合属性, 商业银行也需要培养具备金 融相关知识、网络信息技术、移动互 联网工具应用等多种知识的专业人 才, 为商业银行的创新发展提供新鲜 血液。

\section{7.结论}

就目前的发展状况来看, 互联网 金融尚未达到颠覆商业银行市场地位 的程度, 从积极的方面来看, 互联网 金融起到了倒逼商业银行转型发展的 巨大外部推动力量, 银行要想不成为 “恐龙”，必须要改变传统的经营观 念和模式, 联合互联网金融的网络运 营体系，利用大数据的发展获取更为 广泛的信息，建立良好的金融生态系 统, 联合互联网金融企业, 共同设计 能够满足不同金融需求的金融产品, 在双方竞争与合作的关系中，共同铸 造互联网金融与商业银行的新发展。

\section{参考文献}

[1] 谢平. 迎接互联网金融模式的机遇 和挑战 21 世纪经济报道, 2012 .

[2] 曾刚. 积极关注互联网金融的特点 及发展———基于货币金融理论 视角商业银行家，2012，(11).

[3] 严建红. 互联网时代的金融业一 一一挑战及应对策略 $[\mathrm{J}]$. 国 际金融研究，2001，（6）.

[4] 张常胜. 打造互联网银行 创造新 商业模式 $[\mathrm{J}]$. 互联网金融, 2013, ( 7) .

[5] 张君燕, 谭浩. 移动互联网时代的 商业银行运营框架重构

[ J ] . 商业银行经营管理, 2013 年. 